\title{
OS MÉTODOS ALTERNATIVOS DE RESOLUÇÃO DE CONFLITOS COMO INSTRUMENTOS PARA AEFETIVAÇÃO DO ACESSO À JUSTIÇA
}

\section{ALTERNATIVE METHODS OF CONFLICT RESOLUTION AS TOOLS FOR EFFECTIVE ACCESS TO JUSTICE}

\author{
Juliana Araújo de Mello Canova ${ }^{1}$ \\ Pedro Manoel Abreu²
}

1. Mestranda em Ciências Jurídicas pelo Programa de Pós-Graduação Stricto Sensu em Ciência Jurídica (PPCJ) da Universidade do Vale do Itajaí (UNIVALI), por meio do Programa de Suporte à Pós-Graduação de Instituições de Ensino Particulares (PROSUC/CAPES), na linha de pesquisa de Direito e Jurisdição. Pós-graduanda em Direito Público pela Escola Superior da Magistratura de Santa Catarina (ESMESC). Graduada em Direito pela Universidade do Vale do Itajaí (UNIVALI). Advogada licenciada. Residente Judicial no Tribunal de Justiça de Santa Catarina (TJSC). E-mail: julianamcanova@, gmail.com.

2. Concluiu Pós-doutoramento pela Faculdade de Direito da Universidade de Lisboa, com Projeto e Plano de Estudos sob o título "Processo e Jurisdição: Novas Perspectivas na Cena Contemporânea", sob a Supervisão do Prof. Dr. António Pedro Barbas Homem. Doutor e Mestre em Direito pela Universidade Federal de Santa Catarina (UFSC). Graduado em Direito e em Filosofia pela Universidade Federal de Santa Catarina (UFSC). Docente titular dos Cursos de Mestrado e Doutorado no Programa de Pós-graduação Stricto Sensu em Ciência Jurídica da Universidade do Vale do Itajaí (UNIVALI). Professor, em nível de especialização, da disciplina Sociologia Judiciária da Academia Judicial do Tribunal de Justiça de Santa Catarina (TJSC). Professor convidado do Programa de Pós-Graduação Profissional em Direito da Universidade Federal de Santa Catarina (UFSC), em nível de Mestrado. Magistrado Estadual desde 1975. Foi Juiz titular do TRE/SC, ocupando os cargos de Vice-Presidente e Corregedor. Foi $2^{\circ}$ Vice-Presidente do Tribunal de Justiça de Santa Catarina e Presidente da Corte no biênio 2006-2008. Ex-Diretor Executivo da Academia Judicial e do Centro de Estudos Jurídicos (CEJUR). É Desembargador do Tribunal de Justiça de Santa Catarina (TJSC). E-mail: pedromanoel.abreu@ gmail.com. 
Resumo: Sabe-se que viver em sociedade corresponde à inevitabilidade de conflitos tendo em vista a pluralidade de opiniões, ocorrendo, assim, o surgimento de novas demandas e novos apelos sociais de acordo com as transformações originadas em determinado contexto e momento histórico. Foi, desse modo, que os conflitos deixaram de ser resolvidos unicamente na esfera privada e passaram a ser discutidos pela chamada jurisdição estatal. Todavia, com o passar do tempo, e com a chegada de novas mudanças ocasionadas pela modernidade que afetaram a sociedade, o Estado deixou de ser célere o suficiente quando da prestação da tutela jurisdicional, passando o Poder Judiciário a estar abarrotado de novas contendas a serem resolvidas, na mesma proporção em que as ações já propostas iam sendo finalizadas, dando ensejo à crise do judiciário e, consequentemente, dificultando o acesso à justiça. Entretanto, com a entrada em vigor do Código de Processo Civil de 2015, o legislador buscou a adoção de medidas que objetivassem a resolução de conflitos de forma mais célere e com maiores proveitos para os litigantes, sem que estes ficassem à mercê da morosidade jurisdicional. Nesse panorama, o presente artigo objetiva apresentar uma análise dos métodos alternativos de resolução de conflitos como mecanismo de efetivação do direito de acesso à justiça. Para tanto, destaca-se acerca dos meios não adversariais de resolução de litígios, primeiramente, por meio da indicação das modalidades existentes e suas principais características, e, então, da explanação de como é possível tornar efetivo o acesso à justiça mediante a aplicação de tais métodos.

Palavras-chave: Métodos alternativos de resolução de conflitos. Acesso à justiça. Litígio.

Abstract: It is known that living in society corresponds to the inevitability of conflicts in view of the plurality of opinions, hence the emergence of new demands and new social appeals according to the transformations that took place in a given context and historical moment. It was in this way that conflicts were no longer resolved solely in the private sphere and began to be discussed by the so-called state jurisdiction. However, over time, and with the arrival of new changes caused by modernity that affected society, the State stopped being quick enough when providing jurisdictional protection, and the Judiciary became full of new disputes to be resolved, in the same proportion as the actions already proposed were being finalized, giving rise to the crisis of the 
judiciary, and, consequently, hindering access to justice. However, with the entry into force of the Brazilian Code of Civil Procedure, in 2015, the legislator sought to adopt measures aimed at solving conflicts more quickly and with greater benefits for litigants, without leaving them at the mercy of judicial delays. In this context, this article aims to present an analysis of alternative methods of conflict resolution as a mechanism to enforce the right of access to justice. Therefore, it stands out about the non-adversarial means of resolving disputes, firstly, by indicating the existing modalities and their main characteristics, and then by explaining how it is possible to make access to justice effective through the application of such methods.

Keywords: Alternative methods of conflict resolution. Access to justice. Litigation.

\section{INTRODUÇÃO}

O presente estudo tem como objeto realizar uma análise da possibilidade de se utilizar os métodos alternativos de resolução de conflitos como forma de tornar efetivo o direito de acesso à justiça, e, como objetivo específico explanar brevemente acerca dos diferentes tipos de meios não adversariais de solução de contendas existentes, a exemplo da conciliação e da mediação, e, na sequência, discutir efetivamente sobre a indagação central desta pesquisa, que consiste na análise da utilização dos meios consensuais de solução de litígios como ferramentas capazes de auxiliar na efetivação do acesso à justiça (PASOLD, 2007).

Para tanto, este artigo encontra-se dividido em dois itens.

No primeiro, tecer-se-ão algumas considerações acerca dos métodos alternativos de resolução de conflitos propriamente ditos. Desse modo, destacar-se-ão as principais características de cada uma das figuras classificadas como formas não adversariais de se resolver uma lide, além de se rascunhar brevemente pontuais anotações a respeito de seus conceitos, surgimento e desenvolvimento.

Já no segundo item, abordar-se-á a problemática central deste estudo, que consiste na discussão quanto à utilização dos métodos alternativos de resolução de conflitos como mecanismo de efetivação do direito de 
acesso à justiça, destacando-se, com isso, tópicos pertinentes no que tange à crise do judiciário brasileiro, causada por um abarrotamento jurídico; ao surgimento da jurisdição estatal e, com ela, a criação do direito de acesso à justiça; e à análise de se considerar os meios não adversariais de solução de conflitos como uma maneira capaz de tornar efetivo o acesso à justiça contemplado pelo ordenamento jurídico vigente.

Ademais, o presente artigo se encerra com as considerações finais, nas quais são apresentados pontos conclusivos destacados, seguidos da estimulação à continuidade dos estudos e das reflexões sobre a possibilidade de os direitos humanos contribuírem para o debate de gênero e, igualmente, apresentarem mecanismos de proteção para as mulheres que vivem em países com regimes totalitários na atualidade, seguidas das referências bibliográficas das obras consultadas.

Quanto à metodologia empregada, registra-se que, na fase de investigação foi utilizado o método indutivo; e, na fase de tratamento de dados, o método cartesiano. E o relatório dos resultados expresso no presente artigo é composto na base lógica indutiva (LEITE, 2001) e (PASOLD, 2007).

Nas diversas fases da pesquisa, foram acionadas as técnicas do referente, da categoria, do conceito operacional e da pesquisa bibliográfica (PASOLD, 2007).

\section{MÉTODOS ALTERNATIVOS DE RESOLUÇÃO DE CONFLITOS: MODALIDADES E CARACTERÍSTICAS}

De antemão, imprescindível realizar alguns apontamentos introdutórios acerca da ideia de conflito, posto que se pretende destacar, neste primeiro momento, sobre as formas existentes para se dirimir uma controvérsia. Assim, faz-se cabível delimitar o que se deve entender por conflito.

Sobre isso, valendo-se da definição de Antônio Rodrigues de Freitas Júnior (2009, p. 518): 
[...] situações em que estejam presentes, simultaneamente:

1. no plano objetivo: um problema alocativo incidente sobre bens tidos por escassos ou encargos tidos como necessários, sejam os bens e os encargos de natureza material ou imaterial;

2. no plano comportamental: consciente ou inconsciente, intencional ou não, contraposição no vetor de conduta entre dois sujeitos; e 3. no plano anímico ou motivacional: sujeitos portadores de percepções diferentes sobre como tratar o problema alocativo, como função de valores de justiça.

Dito isso, destaca-se que as demandas podem ser solucionadas por meio da utilização de técnicas de composição adversarial, também conhecida como heterocomposição, ou não adversarial, igualmente chamada de autocomposição, além da possibilidade de se empregar a autotutela ou a autodefesa (GIL, 2020).

No que tange aos métodos adversariais, as partes envolvidas realizam uma espécie de terceirização da resolução da lide, de modo que um terceiro imparcial fique responsável por julgar e empregar o direito ou a equidade. Nesse caso, habitualmente, encontra-se a jurisdição estatal, a jurisdição administrativa e a arbitragem (quando se tratar de jurisdição privada). Ademais, ressalta-se que em nada implicam os sentimentos da parte sucumbente nessa modalidade, bem como é importante sublinhar que a coerção existente aqui se trata de prerrogativa exclusiva da jurisdição estatal, ou seja, do Poder Judiciário (GIL, 2020).

De outro lado, no que concerne à autocomposição, as partes, entre elas ou com o auxílio de terceiros, agem na direção de encontrar a solução para o problema. Isso acontece, comumente, na transação, na conciliação e na mediação, com a possibilidade qualitativa de solucionar a contenda em sua totalidade, levando em consideração a questão sociológica (paz social) e o psicológico das partes conflitantes (paz interior) (GIL, 2020).

Ademais, acerca da terceira e última classificação, grifa-se que a autotutela, também conhecida por autodefesa, consiste, basicamente, na força, ou seja, no poder de coação em si, o que faz com que qualquer noção de justiça seja deixada de lado em segundo plano. Em relação 
ao presente instituto, pode ser resumido como "a busca da justiça pelas próprias mãos" (CUPERTINO, 2002).

Tendo isso em vista, observa-se que a presente pesquisa visa dar ênfase ao segundo grupo de resolução de conflitos, ou seja, à autocomposição, que contempla os métodos alternativos de solução de controvérsias, os quais serão apresentados de forma breve, mas separadamente, na sequência deste item, a fim de que seja possível traçar suas definições e apontar suas principais características.

Nesse panorama, pertinente iniciar com uma reflexão feita pela jurista Fernanda Tartuce, apud Rudolf von Ihering (2018, p. 102), em sua obra, no que diz respeito à utilização dos meios não adversariais. Veja-se:

Rudolf von Ihering, em sua lapidar obra sobre a luta pelo direito, mencionava a possibilidade de, em certas circunstâncias, a autocomposição ser a melhor saída para o conflito: em um simples choque de interesses em que está em jogo só o valor pecuniário do bem, entende-se que o contendor raciocine em termos de relação "custo-benefício" para decidir se irá entrar em juízo ou transigir; em tal caso, a composição dos litigantes, ponto de encontro de um cálculo de probabilidades, seria não só uma saída plausível, mas a melhor das soluções possíveis.

Feito isso, chega o momento de realizar os destaques cabíveis e necessários sobre os mecanismos alternativos de solução de litígios, quais sejam, a conciliação, a mediação, a negociação e a arbitragem.

No que se refere à primeira delas, aponta-se que, de acordo com Alan Junqueira Gil (2020, p. 103), “a conciliação é um processo autocompositivo em que as partes ou os interessados são auxiliados por um terceiro, neutro ao conflito, que visa chegar a uma solução ou a um acordo espontaneamente adotado pelas partes".

No mesmo viés, completa Adolfo Braga Neto (2020, p. 150-151):

A conciliação, genericamente, é uma forma de resolução pacífica de disputas e de lides administrada por um terceiro investido de autoridade decisória ou validatória na questão posta ou delegado por quem a tenha, judicial ou extrajudicialmente, a quem compe- 
te aproximar as partes, gerenciando e controlando as negociações, aparando arestas, sugerindo e formulando propostas, no sentido de apontar vantagens e desvantagens, sempre visando um acordo. Caso as partes não cheguem a esse acordo, na hipótese de frustração da conciliação, a autoridade proferirá a sua decisão.

No mais, cabe ressaltar que, no ordenamento jurídico brasileiro, a prática encontra regulamentação no Código de Processo Civil (Lei $\mathrm{n}^{\circ}$ 13.105/2015) (BRASIL, 2015), podendo ser aplicada nos mais diversos campos do direito, desde a área trabalhista, familiar e empresarial, até a societária e ambiental (GIL, 2020).

No que diz respeito à sua normatização, mais uma vez, nas palavras de Alan Junqueira Gil (2020, p. 113), importante salientar o seguinte:

A conciliação é compulsória, na modalidade judicial, tendo em vista que o artigo 334 do Código de Processo Civil impõe ao juiz a determinada de audiência. A realização da audiência de conciliação no procedimento comum só não ocorrerá se ambas as artes dispensarem a composição consensual ou quando não for admitida a autocomposição, nos termos do $\S 4^{\circ}$ do artigo 165 do Código de Processo Civil.

A conciliação pode ser estipulada por cláusula contratual no intuito de evitar que a controvérsia alcance diretamente à heterocomposição. A cláusula que prevê a conciliação pactuada pelas partes recebe o nome de cláusula escalonada.

O inciso I do artigo 98 da Constituição Federal previu a criação dos juizados especiais pelos Estados e pela União, todavia, os juizados só foram implantados com a Lei n. 9.099/95. [...] Os Juizados Especiais Federais só foram instituídos pela Lei n. 10.2589/2001. [...] Em 2009, a Lei n. 12.153 criou os Juizados Especiais Estaduais da Fazenda Pública [...].

Quanto ao próximo método alternativo de solução de conflitos, pode-se fazer uso da definição concisa de Roberto Portugal Bacellar (2016, p. 107), que estabelece mediação como:

[...] um processo transdisciplinar, é técnica lato sensu e arte que se destina a aproximar pessoas interessadas na resolução de um conflito e induzi-la a perceber no conflito a oportunidade de encontrar, 
por meio de uma conversa, soluções criativas, com ganhos mútuos e que preservem o relacionamento entre elas.

Ainda sobre a figura indicada acima, cumpre ressaltar que as partes em conflito contarão com a ajuda de um terceiro, este devendo ser neutro à lide, ou com um painel de pessoas que não possuam qualquer tipo de interesse no conflito, cujo papel é o de auxiliá-las a chegarem em uma composição. O terceiro em questão é tido como um agente facilitador, ficando responsável por tentar restaurar o vínculo existente entre as partes em discussão (GIL, 2020).

Para terminar, válido, também, apresentar as palavras de Mauro Gaglietti (2013, p. 167-202) em relação ao tema:

[...] Trata-se de um processo de gestão humana de conflitos no qual intervém um terceiro para construir uma situação possível ao (re) estabelecer as condições para que o amor se faça efetivo na vida das pessoas. De modo a ensejar a construção das bases sobre as quais se sustentará a realização da cidadania e a vida social.

[...] Os instrumentos mediadores transformam os desejos e as necessidades dos conflitados, possibilitando a interação, o diálogo e o entendimento, poupando as partes de um desgastante enfrentamento.

Já no que concerne ao instituto da negociação, em suma, definem genericamente Roger Fisher, Willian Ury e Bruce Patton (2005, p. 15) que "a negociação é um meio básico de conseguir o que se quer de alguém, e seja nos negócios, no governo ou na família, as pessoas chegam à maioria das decisões por meio da negociação".

Na mesma linha, outro conceito que se pode adotar é aquele construído por Luiz Antonio Scavone Junior (2019, p. 271), que define o instituto da negociação como sendo:

[...] o conjunto de atos que visam a solução de conflitos das mais variadas espécies, como os conflitos pessoais, profissionais, políticos, diplomáticos, familiares, jurídicos, trabalhistas, empresariais, comerciais etc. 
Outrossim, destaca-se que, na negociação, as partes possuem total controle do processo e do seu resultado, ficando a cargo delas fixar todo e qualquer protocolo a ser seguido. Nesse caso, deve-se ter bem claro que o problema de um é considerado o problema de todos, posto que todas as partes envolvidas apresentam interesse na solução do litígio, desejando, com isso, uma resolução mútua das adversidades (GIL, 2020).

Ademais, de acordo com os ensinamentos de Adolfo Braga Neto (2020, p. 155, grifo nosso), a negociação, no que tange às partes envolvidas, pode receber três classificações distintas. São elas:

A negociação, em relação ao aspecto "partes", pode ser classificada em:

Negociação simples: Caracteriza-se por dela participarem apenas dois polos, sejam eles coletivos, difusos ou individuais. Como exemplos: 1) a negociação direta entre um grupo comprador e um vendedor de um estabelecimento comercial; e 2) a negociação de um consumidor com um fornecedor de serviços.

Negociação multipolos: Nela, há mais de dois polos na negociação, sejam eles coletivos, difusos ou individuais. Por exemplo: uma negociação de compra e venda de um imóvel, em que estão presentes o comprador, o vendedor, o corretor, o cartório e o banco financiador.

Negociacão coletiva: Identifica-se pela existência de um ou mais grupos de sujeitos participantes de um dos polos da negociação, podendo ser coletiva simples ou multipolos. Exemplos são as negociações de um sindicato com determinada indústria pela redução de jornada de trabalho; ou do Poder Público com um grupo social para a desocupação de uma área invadida.

Por último, mas não menos importante, encontra-se o instituto da arbitragem, que, conforme Carlos Alberto Carmona (2004, p. 51), “[...] de forma ampla, é uma técnica para solução de controvérsias por meio da intervenção de uma ou mais pessoas que recebem seus poderes de uma convenção privada, decidindo com base nesta convenção, sem intervenção do Estado [...]”".

Pelo mesmo caminho segue Mariana de Souza Saraiva (2019, p. 28), que conceitua arbitragem como "[...] um meio privado e adequado de solução de controvérsias, pelo qual as partes, fazendo uso da autonomia 
privada, delegam a terceiros, geralmente especialistas na matéria que será discutida, a solução de determinado litígio surgido entre si”.

Além disso, grifa-se que o instituto da arbitragem se encontra regulamentado legalmente pela Lei n. 9.307/1996 (BRASIL, 1996) e pelo Código de Processo Civil (BRASIL, 2015), arts. $3^{\circ}, \S 1^{\circ}$; 189, IV; e 359, bem como sua instauração está autorizada a acontecer de duas maneiras, seja pela consolidação contratual, hipótese de inserção de cláusula específica, ou pelo compromisso arbitral, que se desenvolve por meio de livre negociação entre as partes no instante em que surgem os conflitos (MARASCA, 2013).

Sobre a figura estudada aqui, cabe indicar, ainda, que se trata da modalidade mais adequada para os conflitos que precisam de algum tipo de conhecimento técnico para o seu deslinde, podendo ser utilizada sem restrições em relação às demandas que envolvam direito patrimonial disponível, ou seja, aqueles direitos nos quais as partes envolvidas podem livremente transacionar (contratos em geral, tanto na área civil, comercial, trabalhista e relações de consumo, bastando que o alienante possua plena capacidade jurídica para o fim pretendido) (MARASCA, 2013).

Realizadas tais considerações, encerra-se este item com a certeza de que as informações expostas são capazes de elucidar o que é um conflito, quais as formas existentes para se dirimir uma contenda e, nesse sentido, no que consiste os meios consensuais de solução de controvérsias, reunindo, de forma sucinta e didática, as principais características de cada uma das técnicas que integram à autocomposição (conciliação, mediação, negociação e arbitragem), o que torna possível avançar na discussão do tema proposto.

\section{OS MEIOS ALTERNATIVOS DE RESOLUÇÃO DE CONFLITOS COMO FORMA DE TORNAR EFETIVO O ACESSO À JUSTIÇA}

Diante das definições já estabelecidas anteriormente acerca das práticas que se classificam como meios não adversariais de resolução de 
conflitos, é o momento, então, de passar à análise da problemática central deste artigo. Para tanto, coerente dar início a este segundo item com algumas breves anotações no que toca ao direito de acesso à justiça.

Primeiramente, pertinente apresentar o significado do termo que, segundo José Maria Rosa Tesheiner e Rennan Faria Kruger Thamay (2015, p. 52), objetiva garantir "a possibilidade de levar seus reclames ao Poder Judiciário e deste poder receber uma resposta, qual seja a mais adequada ao caso concreto, visando a uma prestação da tutela jurisdicional efetiva".

Nesse tocante, evidencia-se o pensamento de Fabiana Marion Spengler e Gabriel de Lima Bedin (2013, p. 92-93):

O direito de acesso à justiça é importantíssimo na sociedade contemporânea e possui status de direito fundamental. Ao longo da história, porém, o direito de acesso à justiça passou por inúmeras transformações, sendo entendido e exercido de forma diversa na época antiga, medieval, moderna e contemporânea.

A problemática do direito de acesso à justiça se fez perceber mais intensamente nos Estados liberais burgueses dos séculos XVIII e XIX. O embrião do direito ao acesso à justiça, porém, pode ser apreendido no período antigo, pois se visualizam no Código de Hamurabi as primeiras garantias que podem ser entendidas como inibidoras de opressão entre os indivíduos, bem como o incentivo a estes a procurarem a instância judicial, no caso, o próprio soberano.

Sobre o aspecto história, pontua-se, ainda, nas palavras de Fabiana Marion Spengler e Gabriel de Lima Bedin (2013, p. 94-95):

Na Idade Antiga, portanto, a figura do julgador passou do soberano, por todos os cidadãos, pelo sacerdote e chegou ao pretor, sendo neste último o início da justiça pública, isto é, da jurisdição.

$\mathrm{Na}$ modernidade, sobretudo nos Estados liberais burgueses dos séculos XVIII e XIX, os procedimentos adotados para o tratamento de controvérsias refletiam a filosofia essencialmente individualista dos direitos. Dessa forma, o acesso à justiça restringia-se ao direito formal do cidadão perante o Poder Judiciário de propor ou contestar uma ação.

Enquanto o direito de acesso à justiça era consolidado na Europa (mesmo no período do sistema laissez-faire dos séculos XVIII e 
XIX), no Brasil andava de passos lentos. Do ponto de vista legislativo, havia pouquíssimas referências a um direito próprio e exigível de acesso à justiça.

Quanto a isso, destaca-se que as questões envolvendo o direito de acesso à justiça fizeram-se notar de forma mais acentuada com o surgimento dos Estados liberais burgueses, nos séculos XVIII e XIX, momento no qual o acesso à justiça, ou seja, ao próprio soberano, encontrava-se fortemente conectado à religião. Com o avançar do tempo, durante a Idade Média, a figura do julgador modificou-se: passou do soberano, por todos os cidadãos, na sequência pelo sacerdote, chegando, então, ao pretor, sendo este o marco inicial do que se conhece por justiça pública, em outras palavras, a jurisdição (BEDIN; SPENGLER, 2013).

Com a chegada da Modernidade, o acesso à justiça do cidadão era bem limitado junto ao judiciário, podendo somente iniciar um contestar, uma demanda. Nesse mesmo período, ao passo em que tal direito se mostrava crescendo e ganhando força na Europa, aqui no Brasil a mesma pretensão caminhava vagarosamente, tendo ganhado força apenas na década de 1980 com a edição de diversas leis que ajudaram a tornar concreto o direito de acesso à justiça, a exemplo das seguintes: Lei federal $n^{0}$ 7.019/82 (BRASIL, 1982); Lei federal $n^{\circ}$ 6.938/81 (BRASIL, 1981); Lei federal $n^{\circ} 7.224 / 84$ (BRASIL, 1984); Lei federal $n^{0} 7.347 / 85$ (BRASIL, 1985); Lei federal no $7.853 / 89$ (BRASIL, 1989); Lei federal $\mathrm{n}^{\circ}$ 7.913/89 (BRASIL, 1989); Lei federal no 8.069/90 (BRASIL, 1990); Lei federal $n^{\circ}$ 8.078/90 (BRASIL, 1990); e Lei federal $n^{\circ}$ 9.099/95 (BRASIL, 1995), esta última responsável por instituir os Juizados Especiais Cíveis e Criminais (BEDIN; SPENGLER, 2013).

Ainda no que tange ao direito de acesso à justiça em solo brasileiro, a garantia em questão somente veio a apresentar maior relevância e maior efetividade, conforme mencionado acima, posteriormente a promulgação da Constituição Federal de 1988, o que ocorreu por conta das práticas políticas e jurídicas que ensejaram a universalização da jurisdição diante da adoção de diversas medidas, dentre as quais se pode indicar: a contemplação do princípio da igualdade, a consagração do princípio 
da igualdade material (art. $3^{\circ}$ ); alargamento do conceito de assistência judiciária gratuita (art. 5\% LXXIV), compreendendo também o direito à informação, às consultas e à assistência judicial e extrajudicial; e a previsão de criação dos juizados especiais para julgamento e execução de causas cíveis de menor complexidade e penais de menor potencial ofensivo (art. 98, I) (BEDIN; SPENGLER, 2013).

Visto isso, novamente nas palavras de Fabiana Marion Spengler e Gabriel de Lima Bedin (2013, p. 92-93 e 97-104, grifo nosso), pode-se concluir que:

Dessa forma, o direito ao acesso à justiça sofreu inúmeras transformações importantes ao longo da história, passando da influência direta da religião para o monopólio do Estado laico; de mero direito formal e abstrato para se tornar uma garantia essencial ao Estado Democrático de Direito, bem como fundamental para efetivar a realização de todos os direitos. Com efeito, [...] adquiriu cada vez mais protagonismo, passando a ser entendido como um direito essencial e garantidor dos direitos humanos. [...] evoluiu e se complexou juntamente com a sociedade. Os conflitos deixaram de ser julgados pelo soberano para ser tratados pelo Estado; abandonou-se a inspiração divina como fundamento de decidir, passando a responsabilidade para o Estado laico; e deixou de ser um direito formal do Estado liberal para se transformar em um direito concreto do Estado social, responsável pela concretização dos direitos humanos.

Delineado esse breve panorama histórico dando conta do conceito, surgimento e desenvolvimento do direito de acesso à justiça, depara-se com outro cenário, esse agora, muito atual, fácil de se prever, porém difícil de se modificar, e eis aqui que reside o ponto central deste estudo.

Pois bem.

Sabe-se que fazer parte de uma sociedade complexa e desenvolvida acarreta, inevitavelmente, o surgimento de inúmeras novas demandas e apelos sociais a todo momento. Quando se está em constante movimento e transformação, é esperado que os cidadãos precisem da prestação da tutela jurisdicional cada vez mais, posto novas lides se formarem todos os dias. Entretanto, nota-se, de primeira, que costuma haver muito mais criação e novas contendas que finalização daquelas já existentes. 
E é nesse ponto que o acesso à justiça descarrilha, uma vez que não deve ser garantido tão somente o ingresso junto ao poder judiciário, mas, também, o processamento com celeridade e a resolução da controvérsia levada a juízo.

Nesse panorama, defende Elisângela Nedel Marasca (2013, p. 55):

Diante da grande complexidade da sociedade atual, não é difícil perceber que o monopólio da Justiça pelo poder Judiciário está em crise e necessita de reformas urgentes para suportar o aumento da demanda, bem como para conseguir dar efetividade ao princípio do acesso à Justiça a todos os cidadãos, sem distinção. Diante dos problemas que essa função de poder do Estado enfrenta constata-se que a mesma não possui condições de atingir os resultados que visa a alcançar, ou seja, a composição e a mantença da paz social.

E, na mesma linha, corroboram Pedro Manoel Abreu e Ricardo Tadeu Estanislau Prado (2018, p. 47):

A incapacidade do Poder Judiciário em assimilar a demanda gerada ao longo dos anos culminou em um número estrondoso de processos que aguardam uma solução definitiva, revertendo-se numa Justiça lenta, obstruída e engessada que se rumou para uma crise institucional, a qual se convencionou a denominar "Crise do Judiciário".

Sobre isso, pode-se elencar outros motivos como igualmente responsáveis pela referida crise, a qual encontra base na precariedade dos meios que direcionam aos órgãos jurisdicionais do Estado, quais sejam, a ineficácia dos meios de acesso à justiça; a ausência de investimentos para manutenção e ampliação da estrutura dos órgãos do jurisdicionado; bem como a natureza ritualista dos instrumentos processuais nacionais. Outrossim, o período de duração do processo e o seu custo também correspondem a uma barreira considerável para a tranquilidade da coletividade. Tais componentes, como é de se notar de imediato, coincidem para diminuir e tornar mais difícil o canal de acesso à justiça por meio do processo estatal (CUPERTINO, 2002).

É nesse contexto, tendo em vista o aumento considerável do número de ações propostas que precisam alcançar a prestação da tutela jurisdicional, encontrando-se o judiciário, desse modo, abarrotado, que os 
métodos alternativos de solução de conflitos entram em cena como uma forma de tornar o direito de acesso à justiça efetivo, visto que carregam, com suas técnicas, a possibilidade de solucionar as lides de maneira muito mais célere, garantindo que um grande número de litigantes possa ver suas pretensões satisfeitas, bem como oportunizar àqueles que se declaram financeiramente menos favorecidos a resolução dos seus litígios, os quais, por muitas vezes, por conta da classe social a que pertencem as partes envolvidas, não chegam sequer a ser discutidos no judiciário, ou acabam não seguindo o curso processual que é esperado, posto os entraves que podem surgir.

Sobre o tema, Elisângela Nedel Marasca (2013, p. 56) faz algumas observações importantes e esclarecedoras:

Obstáculos econômicos, sociais, culturais, psicológicos e legais impedem o acesso à Justiça.

Em virtude dessas várias barreiras ocorre uma descrença da população em relação às instituições estatais encarregadas de distribuir justiça, acreditando-se que ela não é destinada aos indivíduos pobres, mas somente para aqueles que desfrutam de grande poder econômico.

Em virtude de os métodos tradicionais de resolução dos conflitos não conseguirem atender às necessidades sociais cada vez mais crescentes e complexas da população, os próprios indivíduos passaram a buscar, com mais frequência, meios consensuais para solucionar seus conflitos.

Nesse espectro, ainda nas palavras de Elisângela Nedel Marasca (2013, p. 56), conclui-se que:

Assim, a sociedade espera ansiosa pela instituição de novas técnicas de solução dos conflitos que venham, não como salvadoras, mas como auxiliares e incrementadoras das que já aplicamos hoje, pois só assim a população carente de oportunidades e recursos, que já é tão penalizada pelo destino, vivendo à margem da sociedade, poderá realmente ter acesso efetivo à Justiça e, conseqüentemente (sic), a realização da cidadania de forma plena.

Cumpre destacar, ainda, segundo André Gomma de Azevedo, que atualmente $(2011$, p. 14) “[...] o conceito de acesso à Justiça está intrin- 
secamente ligado à contínua redução de insatisfações com o sistema público de resolução de conflitos”.

Assim, ao olhar para o atual cenário brasileiro, é preciso prestar atenção às vantagens que as modalidades não contenciosas de resolução de controvérsias podem proporcionar a todos, em especial no que tange ao direito de acesso à justiça. Deve-se ter em mente, e bem claro, que não se trata de técnicas visando diminuir o trabalho dos profissionais da advocacia, muito menos modificar a competência do Judiciário, longe disso, uma vez que são encaradas por diversos juristas como procedimentos que existem na intenção de ajudar, acrescentar, fomentar, e não para prejudicar (MARASCA, 2013).

Nesse panorama, vislumbra-se, em suma, um sistema judiciário que atravessa uma fase conturbada, marcada por um número de ajuizamento de novas demandas muito superior à finalização das lides já em andamento e que, no meio desse cenário um tanto quanto caótico, encontrou, nas formas não adversariais de resolução de conflitos, um forte mecanismo aliado para que se consiga efetivamente garantir o direito de acesso à justiça para todos.

\section{CONCLUSÃ̃}

Verifica-se que fazer parte de uma sociedade significa que, inevitavelmente, com o passar do tempo, novas demandas surgirão, trazendo as mais diversas matérias a serem tuteladas. Tais contendas, por conta das modificações promovidas e sofridas pelo contexto em que se está inserido, culminarão em novos desafios a serem enfrentados e problemas a serem resolvidos, devendo, para tanto, sempre ser levada em consideração a necessidade de se refletir acerca da melhor resposta que se pode dar e como ela pode ser dada.

Dito isso, pontua-se que, em relação à temática abordada neste artigo, foi possível aprender que os conflitos deixaram de ser resolvidos única e exclusivamente na esfera privada e passaram a ser discutidos pela chamada jurisdição estatal. Ocorre, entretanto, que, com a chegada de novas mudanças ocasionadas pela modernidade, o Estado deixou de 
ser célere o suficiente quando da prestação da tutela jurisdicional, deixando, então, de prestar assistência a muitas pessoas, não conseguindo, assim, dar efetividade ao direito de acesso à justiça.

Nesse panorama, conclui-se que, basicamente, o sistema judiciário brasileiro vem atravessando uma fase um tanto quanto conturbada, a qual se convencionou chamar de crise do judiciário, marcada por um número de ajuizamento de novas demandas muito superior à finalização das lides que já estão em andamento. No meio desse cenário um tanto quanto caótico, encontra-se, nos métodos alternativos de resolução de conflitos (conciliação, mediação, arbitragem e negociação), um forte mecanismo aliado para que se consiga efetivamente garantir o direito de acesso à justiça a todos, visto que as técnicas aqui mencionadas, muitas vezes, são invocadas de forma voluntária pelas partes envolvidas, bem como se tratam de procedimentos que só acrescentam positivamente à relação jurídica.

\section{REFERÊNCIAS}

ABREU, Pedro Manoel; PRADO, Ricardo Tadeu Estanislau. A desjudicialiazação dos conflitos e a desburocratização da justiça como alternativas para desobstruir o judiciário e melhorar o acesso à justiça. In: MARTINI, Sandra Regina; FREITAS, Sérgio Henriques Zandona; RIBEIRO, Darci Guimarães (Coord.). XXVII CONGRESSO NACIONAL DO CONPEDI PORTO ALEGRE/RS. ACESSO À JUSTIÇA I. CONPENDI: Florianópolis, 2018. p. 45-63. Disponível em: http:// conpedi.danilolr.info/publicacoes/34q12098/6tp3x9v4/XnUdLXGuN6kh00bg.pdf. Acesso em: 11 fev. 2021.

AZEVEDO, André Gomma de. Desafios de acesso à justiça ante o fortalecimento da autocomposição como política pública nacional. In: PELUSO, Antonio Cezar; RICHA, Morgana de Alemeida (coord.). Conciliação e mediação: estruturação da política judiciária nacional. Rio de Janeiro: Forense, 2011.

BACELLAR, Roberto Portugal. Mediação e arbitragem. São Paulo: Saraiva, 2016. 
BRAGA NETO, Adolfo.et al. Negociação, mediação, conciliação e arbitragem: curso de métodos adequados de solução de controvérsias. 3. ed. rev. ampl. e atual. Rio de Janeiro: Forense, 2020. 429 p.

BRASIL. Lei $\mathbf{n}^{\mathbf{0}} \mathbf{6 . 9 3 8}$, de 31 de agosto de 1981. Dispõe sobre a política nacional do meio ambiente, seus fins e mecanismos de formulação e aplicação, e dá outras providências. Brasília, DF: Presidência da República, [1981]. Disponível em: http://www.planalto.gov.br/ccivil_03/ leis/16938.htm. Acesso em: 2 jul. 2021.

BRASIL. Lei $n^{0}$ 7.019, de 31 de agosto de 1982. Altera o Código de Processo Civil, para simplificar o processo de homologação judicial da partilha amigável e da partilha de bens de pequeno valor. Brasília, DF: Presidência da República, [1982]. Disponível em: https://presrepublica.jusbrasil.com.br/legislacao/103472/lei-7019-82. Acesso em: 2 jul. 2021.

BRASIL. Lei $\mathbf{n}^{\mathbf{7}} \mathbf{7 . 2 4 4}$, de 7 de novembro de 1984.Dispõe sobre a criação e o funcionamento do Juizado Especial de Pequenas Causas. Brasília, DF: Presidência da República, [1984]. Disponível em: http:// www.planalto.gov.br/ccivil_03/leis/1980-1988/17244.htm. Acesso em: 2 jul. 2021.

BRASIL. Lei no 7.347, de 24 de julho de 1985. Disciplina a ação civil pública de responsabilidade por danos causados ao meio-ambiente, ao consumidor, a bens e direitos de valor artístico, estético, histórico, turístico e paisagístico (VETADO) e dá outras providências. Brasília, DF: Presidência da República, [1985]. Disponível em: http://www.planalto. gov.br/ccivil_03/leis/17347orig.htm. Acesso em: 2 jul. 2021.

BRASIL. Lei $\mathbf{n}^{\mathbf{7}} \mathbf{7 . 8 5 3}$, de 24 de outubro de 1989. Dispõe sobre o apoio às pessoas portadoras de deficiência, sua integração social, sobre a Coordenadoria Nacional para Integração da Pessoa Portadora de Deficiência - Corde, institui a tutela jurisdicional de interesses coletivos ou difusos dessas pessoas, disciplina a atuação do Ministério Público, define crimes, e dá outras providências. Brasília, DF: Presidência da República, [1989]. Disponível em: http://www.planalto.gov.br/ccivil_03/ leis/17853.htm. Acesso em: 02 jul. 2021. 
BRASIL. Lei $\mathbf{n}^{\mathbf{0}}$ 7.913, de 7 de dezembro de 1989. Dispõe sobre a ação civil pública de responsabilidade por danos causados aos investidores no mercado de valores mobiliários. Brasília, DF: Presidência da República, [1989]. Disponível em: http://www.planalto.gov.br/ccivil_03/leis/17913.htm. Acesso em: 02 jul. 2021.

BRASIL. Lei no 8.069, de 13 de julho de 1990.Dispõe sobre o Estatuto da Criança e do Adolescente e dá outras providências. Brasília, DF: Presidência da República, [1990]. Disponível em: http://www.planalto. gov.br/ccivil_03/leis/18069.htm. Acesso em 02 jul. 2021.

BRASIL. Lei $n^{0}$ 8.078, de 11 de setembro de 1990. Dispõe sobre a proteção do consumidor e dá outras providências. Brasília, DF: Presidência da República, [1990]. Disponível em: http://www.planalto.gov. br/ccivil_03/leis/18078compilado.htm. Acesso em: 02 jul. 2021.

BRASIL. Lei $\mathbf{n}^{0}$ 9.099, de 26 de setembro de 1995. Dispõe sobre os Juizados Especiais Cíveis e Criminais e dá outras providências. Brasília, DF: Presidência da República, [1995]. Disponível em: http://www. planalto.gov.br/ccivil_03/leis/19099.htm. Acesso em: 02 jul. 2021.

BRASIL. Lei $\mathbf{n}^{0}$ 9.307, de 23 de setembro de 1996.Dispõe sobre a arbitragem. Brasília, DF: Presidência da República, [1996]. Disponível em: http://www.planalto.gov.br/ccivil_03/leis/19307.htm. Acesso em: 02 jul. 2021.

BRASIL. Lei no 13.105, de 16 de março de 2015. Código de Processo Civil. Brasília, DF: Presidência da República, [2015]. Disponível em: http://www.planalto.gov.br/ccivil_03/_ato2015-2018/2015/lei/113105. htm. Acesso em: 02 jul. 2021.

CARMONA, Carlos Alberto. A arbitragem e o processo: comentários à lei 9.307/96. São Paulo: Malheiros, 2004.

CUPERTINO, Cláudio. Os métodos alternativos de resolução de conflitos e a tecnologia da informação como instrumentos de acesso à justiça. Dissertação (Mestrado). Universidade Federal de Santa Catarina. Centro Tecnológico. Programa de Pós-Graduação em Engenha- 
ria de Produção. 2002. Disponível em: http://repositorio.ufsc.br/xmlui/ handle/123456789/83568. Acesso em: 8 fev. 2021.

FISHER, Roger; URY, Willian; PATTON, Bruce. Como chegar ao sim: a negociação de acordos sem concessões. Rio de Janeiro: Imago, 2005

FREITAS JÚNIOR, Antônio Rodrigues de. Conflitos de justiça e limites da mediação para a difusão da cultura da paz. In: SALLES, Carlos Alberto de (coord.). As grandes transformações do processo civil brasileiro. São Paulo: Quartier Latin, 2009. p. 518.

GIL, Alan Junqueira. Mecanismos alternativos de resolução de conflitos: a solução para a garantia do acesso à justiça. Dissertação (Mestrado em Direito). Universidade Nove de Julho. São Paulo, 2020. Disponível em: http://bibliotecatede.uninove.br/handle/tede/2402. Acesso em: 10 fev. 2021.

LEITE, Eduardo de oliveira. A monografia jurídica. 5. ed. São Paulo: Revista dos Tribunais, 2001.

MARASCA, Elisângela Nedel. Meios alternativos de solução de conflitos como forma de acesso à justiça e efetivação da cidadania. Revista Direito em Debate, v. 16, n. 27-28, 25 mar. 2013. Disponível em: https://revistas.unijui.edu.br/index.php/revistadireitoemdebate/article/ view/66. Acesso em: 5 fev. 2021.

PASOLD, Cesar Luiz. Prática da pesquisa jurídica e metodologia da pesquisa jurídica. 10 ed. Florianópolis: OABSC Editora, 2007.

SARAIVA, Mariana de Souza. O financiamento por terceiros na arbitragem e o acesso à justiça. Rio de Janeiro: Lumen Juris, 2019.

SCAVONE JUNIOR, Luiz Antonio. Arbitragem: mediação, conciliação e negociação. Rio de Janeiro: Forense, 2019.

SPENGLER, Fabiana Marion (org). Acesso à justiça, direitos humanos \& mediação. Organização de Fabiana Marion Spengler e Gilmar Antonio Bedin. 22. ed. Curitiba: Multideia, 2013. 260 p. 
TARTUCE, Fernanda. Mediação nos conflitos civis. 4. ed. rev. atual. e ampl. Rio de Janeiro: Forense; São Paulo: MÉTODO: 2018. p. 102.

TESHEINER, José Maria Rosa; THAMAY, Rennan Faria Kruger. Teoria geral do processo: em conformidade com o novo CPC. Rio de Janeiro: Forense, 2015.

Recebido em: 30/06/2021

Aprovado em: 05/07/2021 